\title{
Pulsed electric field before Kobe and Izu earthquakes from Seismically-induced Anomalous Animal Behavior (SAAB)
}

\author{
Institute of Earth and Space Science, Graduate School of Science, Osaka University, I-I Machikaneyama, Toyonaka, Osaka 560, Japan \\ Kobe Oji Zoo, 3-I Oji. Nada, Kobe 657, Japan \\ Atagawa Tropical \& Alligator Garden, Atagawa, Itoh-cho, Kamo. Shizuoka 413-03, Japan
}

Sea lions, hippopotamus and crocodiles in the Kobe-Oji Zoo were reported to have shown seismic anomalous animal behavior ( $S A A B)$ before the Kobe Earthquake. Crocodiles at the Izu-Atagawa Banana-Alligator Garlen were observed to have cried before volcanic erupions and earthquakes in the Izu area. Critical electric ield intensity which causes a field-avoidance behavior has been estimated for these animals and some reptiles. Behavioral responses to seismic electric pulse stimuli lue to the emerged pulsed charges or electromagnetic vaves were tentatively attributed to the cause of $S A A B$. Seismic field intensities prior to the Kobe Earthquake were estimated from the electric field effects and citi-en's statements on SAAB are shown in a geographic map with the number of statements. The anecdotal reports of significant animal disturbances at the epicenter were entirely consistent with the electric field effects. An attempt was made to observe natural electric pulses prior to earthquakes with a digital storage oscilloscope conforming to geophysical theory, also at the time of lightning and by electric discharges. Some electric pulses were detected simultaneously occurring in a laboratory with startled movements of eels as well as with fighting and grooming of hamsters known as anomalous behavior caused by electric field effects.

\section{Introduction}

It has long been discussed that animals become excited and fall into panic before earthquakes as if they are sensitive to their onset (Masuya, 1955; Rikitake 1978; Tritusch, 1978). Anomalous behavior was observed for animals at the Kobe-Oji Zoo in a day heading up to the Kobe Earthquake on January 17, 1995. Sea lions cried and would not calt, while hippopotami sank into their pool and would not reface, crocodiles became violent and left scratches to the glass wall of their enclosure. It was also reported that fish and silkworms aligned themselves in a common direction prior to the Kobe Earthquake and some fish died in panic by jumping out of water. Earthworms came out of the earth and swarmed. It was not surprising therefore to find Wadatsumi (1995) collecting from citizens through faxes and internets and reporting 1519 statements in which most animals were claimed to show seismically-induced anomalous animal behavior (SAAB) before the Kobe Earthquake. The behavior is not confined to the Kobe Earthquake; crocodiles at the Izu-Atagawa Tropical \& Alligator Garden were photographed for crying and behaving violently before volcanic eruptions and earthquakes in the lzu area.

Scientists are skeptical and regard SAAB as just a superstition or as retrospectively asserted stories after an earthquake under the psychologically abnormal condition caused by a natural disaster. However, they may have detected some kind of intense signals such as sounds, odor, electric or magnetic stimuli before carthquakes (Bushirk et al., 1981). The Japanese folk story that catfish cause earthquakes was once studied from the viewpoint of seismic electric fields (Abe, 1932). More recent investigations suggest that there could be some biological basis to these claims.

Seismic activity in fault movement could be modeled as an electromagnetic phenomenon (Ikeya and Takaki, 1996) and produces seismic transient free charges by means of a piezoelectric effect of such intensity to cause lightning discharges sometimes observed in connection with earthquakes. Ikeya et al (1996) showed that $\mathrm{SAAB}$ might be related with the charge effects in precursory earthquake swarms. Laboratory experiments with electric fields reproduced the alignment behavior and mysterious shape of candle flame (Ikeya and Matsumoto, 1997) reported anecdotally.

This paper describes the estimated seismic electric field intensity and its direction before the Kobe Earthquake from the statements, assuming that they are correct, and from experimental data on the response of sea lions, penguins and snakes to electric fields in the Kobe-Oji Zoo. Crocodiles at the Izu-Atagawa Tropical \& Alligator Garden were also studied. Pulsed electric field measurements in water were attempted with a digital storage oscilloscope.

\section{Experimental}

\section{Location and animals}

The Kobe Oji Zoo

The Kobe Oji Zoo is located about $25 \mathrm{~km}$ away from the north edge of the Nojima Fault that moved in the Kobe Earthquake. California sea lions, hippopotami, penguins, flamingos and green snakes were used for the study of electric field effects.

\section{Atagawa Tropical Banana and Alligator Garden}

Crocodiles in this zoo cried and behaved violently before volcanic eruptions at Izu-Ohshima in 1971 and before earthquakes. Alligators 
alleged responded to approaching thunder storms, while crocodiles neglected them.

\section{Apparatus}

Iron-mesh barbecue nets covered with an aluminum cooking foil were used as electrodes of $0.5 \mathrm{~m} \mathrm{x} 0.7 \mathrm{~m}$ and dipped into a pool at separations $d$, from 1 to $5 \mathrm{~m}$. The electrode resistance is less than 1 $\mathrm{ohm}$. The DC voltage was generated using either a home-made battery pack having a series-connected twelve $1.5 \mathrm{~V}$ batteries connected in series or a series of ten $9 \mathrm{~V}$ batteries. Electric fields were applied by switching the batteries on and off. The electric pulses were applied using a commercial 'Elepulse (Omuron HV-FO4)' for the electronic massage apparatus.

\section{Determination of critical electric field}

Responses of animals to the fields were recorded using a commercial video recorder. Electric field intensity estimated by dividing the applied voltage by the distance is not accurate in a big pool where the electrode separation of $5 \mathrm{~m}$ is much larger than the length of the electrode, $0.5 \mathrm{~m}$, so the static field intensities at several sites were calculated using an electric field simulator for the electrode separation of $5 \mathrm{~m}$ and the applied voltage of $100 \mathrm{~V}$ as shown in Figure. 1 .

\section{Observation of pulsed electric field in an aquarium}

Parallel plate electrodes with a separation of $20 \mathrm{~cm}$ were placed in an aquarium. Electric noises were observed with a digital storage oscilloscope (DSO:A\&D Co., AD-5146) with a triggering level of 10 noises less than this level was not recorded. The sampling frequency is 40 million samplings per second with storage memories of 2048 bytes. The data was transfered to a computer hard disc in $12 \mathrm{~s}$ which is a dead time during which no observational data is measured with DSO.

\section{Electric field effects on animals}

\section{Animals at the Kobe-Oji Zoo \\ California sea lions}

Electric field intensities which caused abnormal behavior at the Kobe Oji Zoo were evaluated from an experiment on the effects of electric fields on sea lions and hippopotami. Sea lions seemed to be noticed the electric field and returned as shown in Figure 2 from the position of the electric field intensity of $0.5 \mathrm{~V} / \mathrm{m}$ as estimated from the calculated results in Figure 1. They cried and did not approach the high field area close to the electrodes. They did not eat for a few hours. This result indicates that the minimum seismic electric field is $0.5 \mathrm{~V} / \mathrm{m}$ for sea lions.

\section{Hippopotamus}

This animal sank and did not appear before the Kobe Earthquake. The electrode separation of $20 \mathrm{~m}$ required by the size of the hippopotamus made it difficult to accurately estimate the electric field in the experiment. Approximate field strength when the hippopotamus approached the electrode and sank was around $6.5 \mathrm{~V} / \mathrm{m}$. No

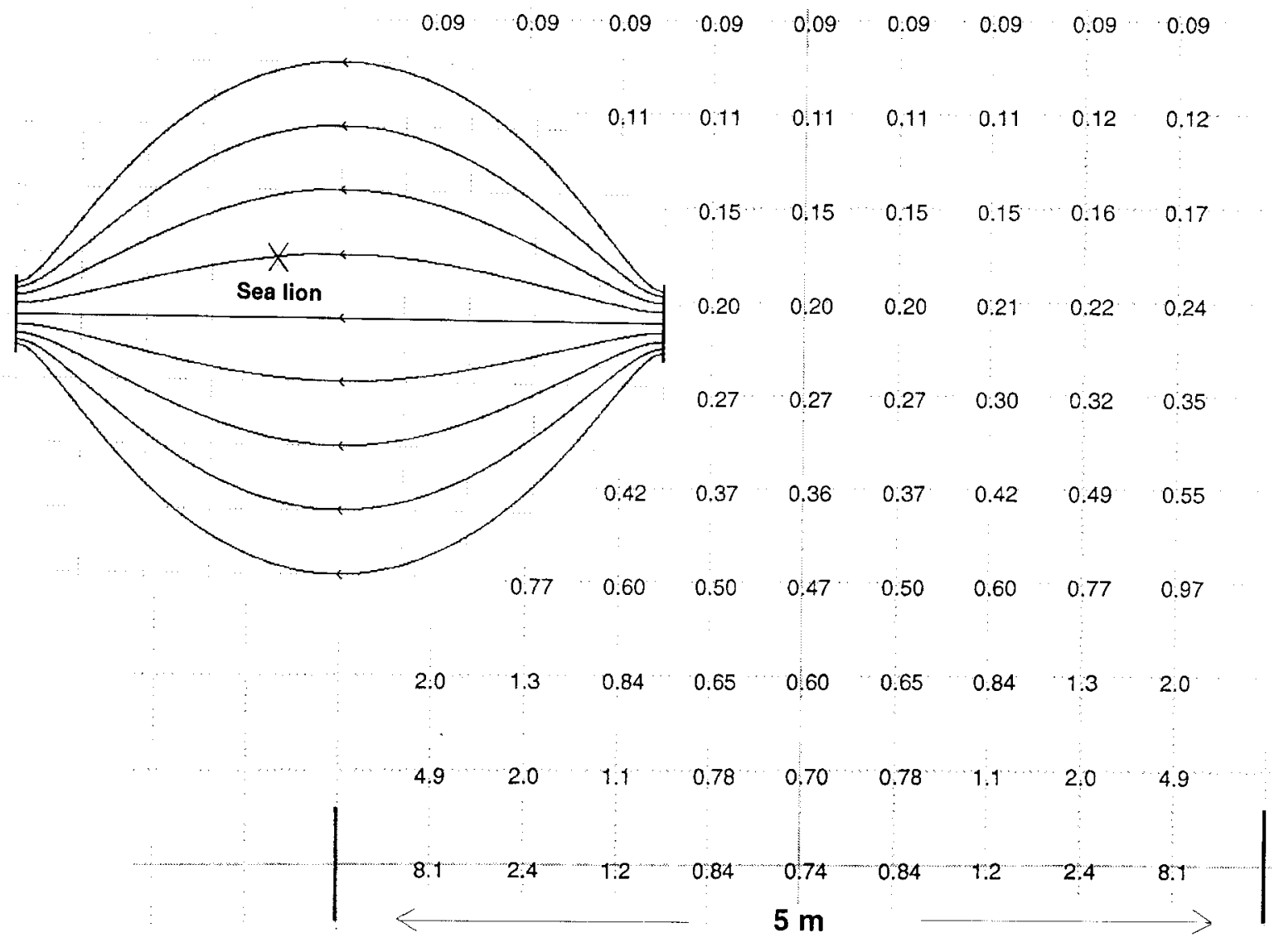

Figure 1 Calculated electrostatic field intensity at each mesh site for an electrode separation of $5 \mathrm{~m}$ and a voltage of $100 \mathrm{~V}$ in a pool. One can estimate the electric field intensity which animals detect from the behavior at the particular site. Applied field in the experiment was from 1.5 to $90 \mathrm{~V}$. Sea lions approaching to the electrode returned at the indicated site from which the field intensity of $0.5 \mathrm{~V} / \mathrm{m}$ was estimated. 


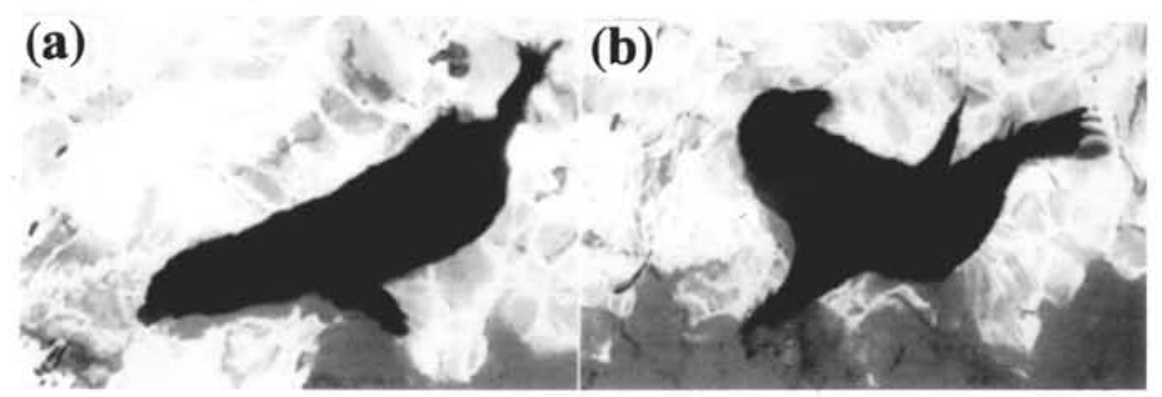

Figure 2 Response of a sea lion in the pool of the Kobe-Oji Zoo to an electric pulse of about $0.5 \mathrm{~V} / \mathrm{m}$.

(a) swimming normally,

(b) noticed a weak electric field pulse having a peak intensity of about $0.5 \mathrm{~V} / \mathrm{m}$,

(c) returned quickly and

(d) avoiding field.
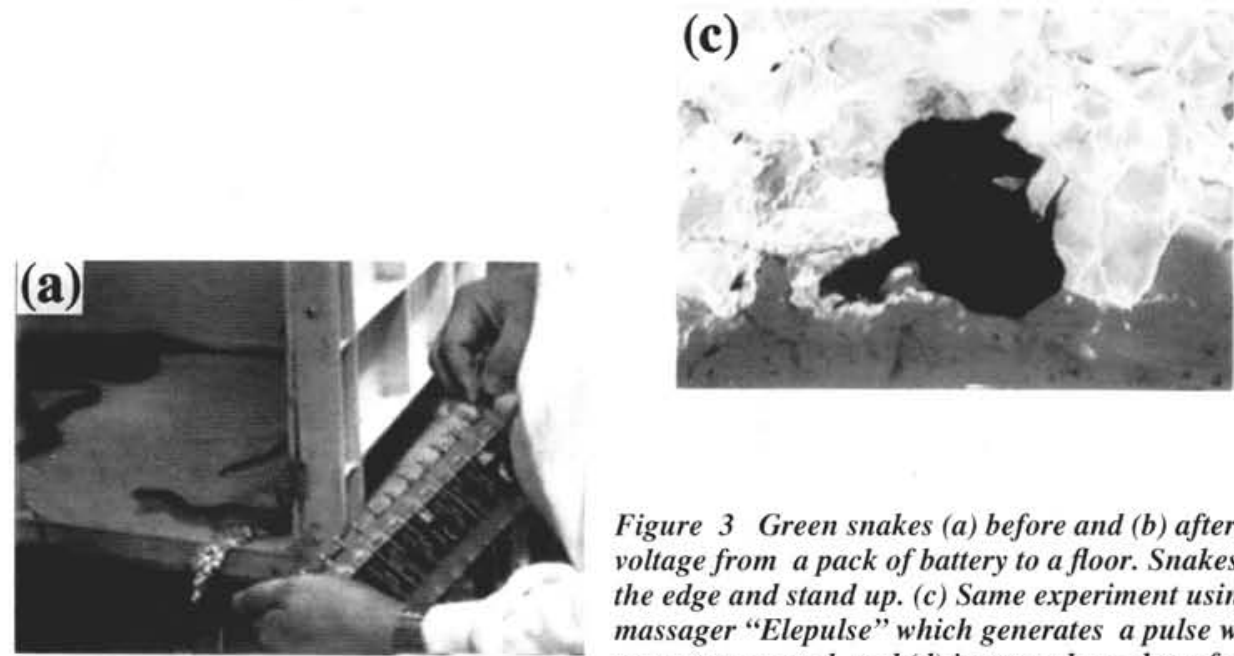

(d)

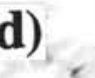

Figure 3 Green snakes (a) before and (b) after electric shock applying DC voltage from a pack of battery to a floor. Snakes avoided field by swarming to the edge and stand up. (c) Same experiment using a health-care electronic massager "Elepulse" which generates a pulse with the width of 1 microsecond every one second, and (d) increased number of pulses made snakes winded.
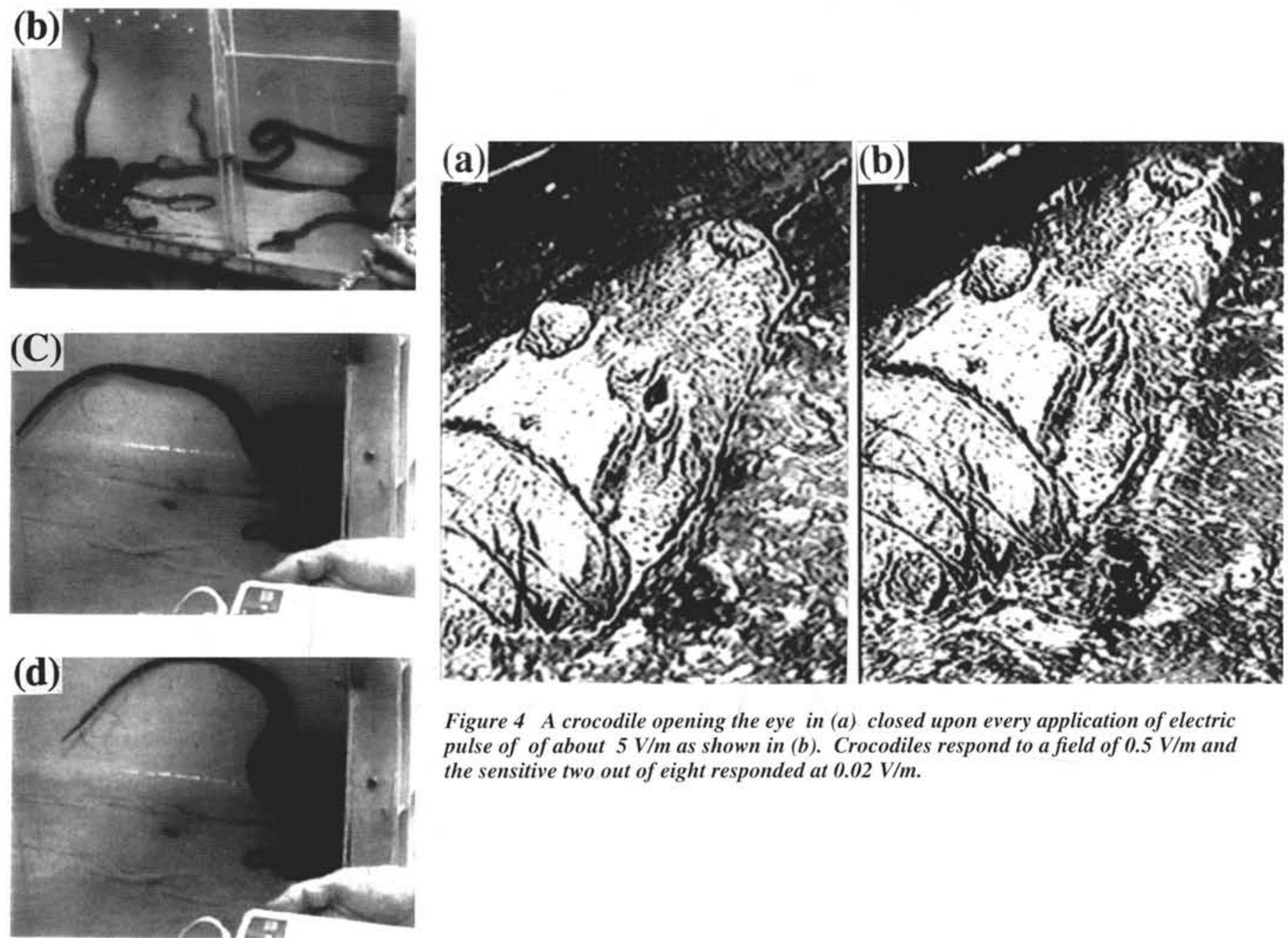

Figure 4 A crocodile opening the eye in (a) closed upon every application of electric pulse of of about $5 \mathrm{~V} / \mathrm{m}$ as shown in (b). Crocodiles respond to a field of $0.5 \mathrm{~V} / \mathrm{m}$ and the sensitive two out of eight responded at $0.02 \mathrm{~V} / \mathrm{m}$. 
Table I Electric field effects on animals at the Kobe-Oji Zoo (KOZ), the Izu-Atagawa Tropical \& Alligator Garden (IATAG) together with some results on fish and reptiles in a laboratory.

\begin{tabular}{|c|c|c|}
\hline Animal & $\mathbf{F}(\mathbf{V} / \mathbf{m})$ & Responses \\
\hline \multicolumn{3}{|l|}{ The Kobe-Oji Zoo (KOZ) } \\
\hline California Sea Lion & 0.5 & Quick avoidance from field \\
\hline Otariidae Zalophus californianus & & no longer approachs electrodes \\
\hline Hippopotamus (KOZ) & 6.5 & No clear reaction, merely submerge \\
\hline Flamingo & 4 & Puffing up? no clear reaction \\
\hline Goose & 15 & Puffing up? slight compulsion? \\
\hline Penguin & 15 & Reduced appetite, avoiding? \\
\hline Pelican & 14 & No clear reaction \\
\hline \multirow[t]{3}{*}{ Snake (Green snake) } & 66 & Startled movement \\
\hline & 90 & Reacted to pulse with shock \\
\hline & 114 & Muscle cramped \\
\hline \multirow[t]{2}{*}{ cf. Rat (Ratus norvegicus) a) } & 2 & Grooming \\
\hline & 72 & Cramps in legs \\
\hline Sparrow (Amandava) ${ }^{a)}$ & 100 & Puffing up? grooming \\
\hline \multicolumn{3}{|c|}{ Izu-Atagawa Tropical \& Alligator Garden (IATAG) } \\
\hline \multicolumn{3}{|c|}{ (a) Young crocodiles $(\mathrm{L}=1 \mathrm{~m}, \mathrm{~d}=1.5 \mathrm{~m})$} \\
\hline Spectacled caiman & 1 & One sensitive specimen bit electrodes \\
\hline Caiman crocodilus (LINNE) & 2 & Two bit electrodes \\
\hline $\mathrm{R}_{\text {leg-leg }}>40 \mathrm{M} \Omega$ & 5 & All moved \\
\hline$R_{\text {belly-mouth }}=2 \mathrm{M} \Omega$ & 8 & Legs cramped, all responded \\
\hline Paraguay caiman & 3.7 & No clear response \\
\hline Caiman crocodilus yacare (DAUOIN) & 5 & Eye closed by switching on, \\
\hline $\mathrm{R}_{\text {leg-leg }}>40 \mathrm{M} \Omega$ & 6.2 & Jaw compulsions \\
\hline \multicolumn{3}{|l|}{$\mathrm{R}_{\text {belly-mouth }}>40 \mathrm{M} \Omega$} \\
\hline \multicolumn{3}{|l|}{$\begin{array}{l}\text { (b) Baby crocodiles }(30-40 \mathrm{~cm}) \mathrm{d}=22 \mathrm{~cm} \\
\text { (Field perpendicular to the body) }\end{array}$} \\
\hline Nilotic crocodile & 0.5 & Eye movement (only 1 specimen of 3 ) \\
\hline \multirow[t]{4}{*}{ Crocodylus niloticus LAURENTI } & $6-7$ & Eye \& front leg movement \\
\hline & 20 & Compulsion of front $\&$ rear legs \\
\hline & 35 & Compulsion of head \\
\hline & 50 & Compulsion of jaw \& eyes \\
\hline Mugger, Marsh crocodile & $6-7$ & Movement of eyes \& rear legs \\
\hline \multirow[t]{3}{*}{ Crocodylus palustris LESSON } & 13 & Movement of front \& rear legs \\
\hline & $20-27$ & Compulsion of all four legs \\
\hline & 40 & Eyes closed, cramp, run away \\
\hline Turtle from Thailand & 2 & Startled movement, retracted head \\
\hline \multirow[t]{2}{*}{ Hieremis annandali Boulenger } & 4 & Opened and closed eyes \\
\hline & 12 & Washed face \\
\hline \multirow[t]{2}{*}{ Snake (Bore Confrictor) } & 15 & Responses in tail and tongue \\
\hline & & Adoption of S-configuration in neck \\
\hline \multirow[t]{2}{*}{ cf. Goldfish al } & 15 & Startled reaction to initial pulse \\
\hline & 23 & Oriented body perpendicular to field \\
\hline
\end{tabular}

a) Responses depend on individuals and species (Ikeya et al. 1996b)

b) Almost the same as Japanese minnows and other fish (Ikeya et al. 1996a) 


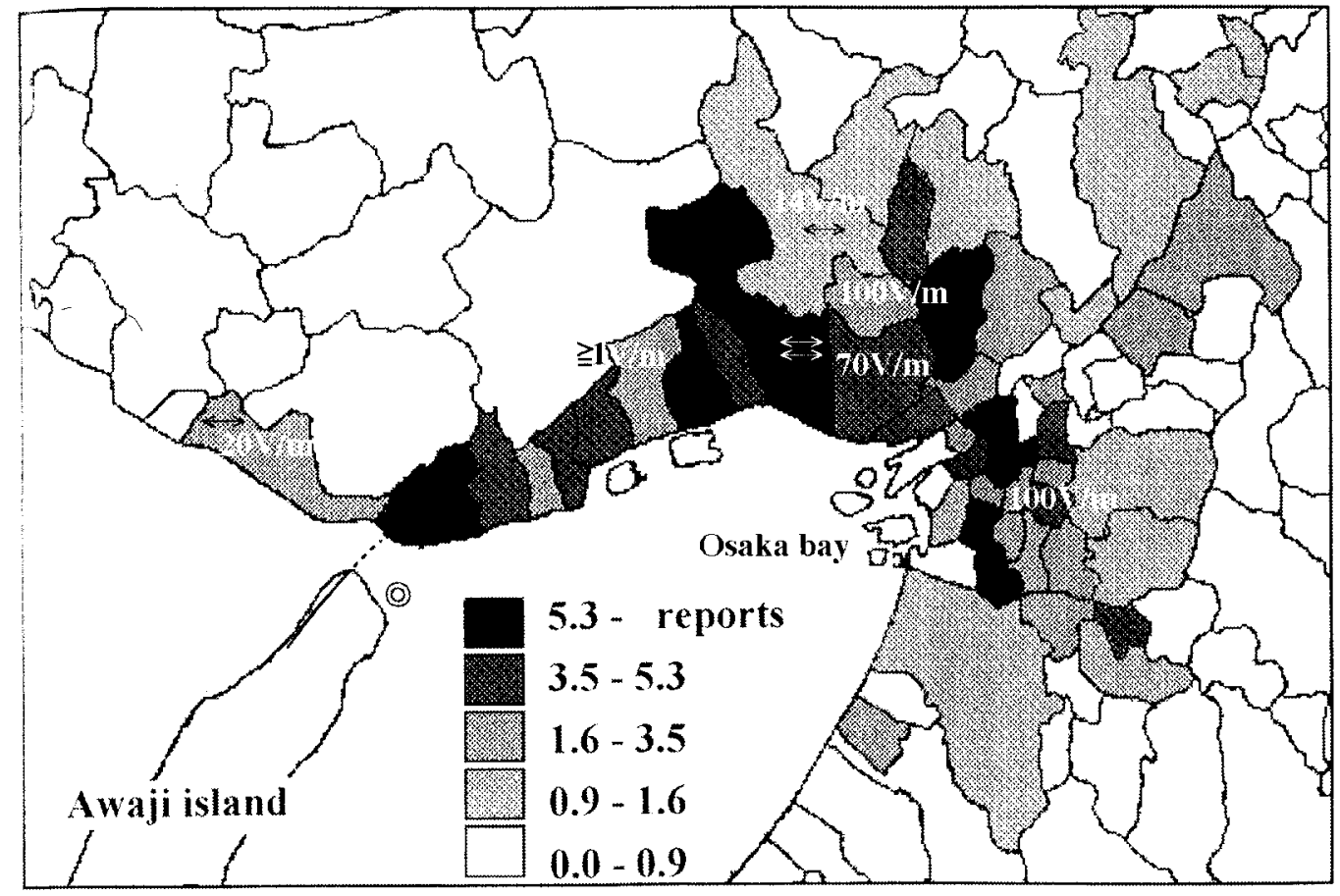

Figure 5 (a) Estimated directions and intensities of preseismic electric fields at several places from the reported seismically-induced anomalous animal behavior (SAAB) before the Kobe Earthquake. (b) Vumbers of reported $S A A B$ per $10 \mathrm{~km}^{2}$ before the Kobe Earthquake are indicated in the map together with the fault (line) and epicenter (double circles). The field direction was estimated from the direction of floating fish. Electric field pulses or wave packets of electromagnetic waves may be responsible.

Crocodile (Family Crocodylidae)

Paraguay caiman (Caiman crocodilus vacare (DAUOIN)): The eye response (closing and opening when the DC field was switched on and off as shown in Figure 4 (a) and (b) ) was observed at 5 $\mathrm{V} / \mathrm{m}$. The movement of the mouth (compulsion) started at $6 \mathrm{~V} / \mathrm{m}$. They became excited and violently bit the electrodes at $9 \mathrm{~V} / \mathrm{m}$ and suffered body compulsion for fields of $20 \mathrm{~V} / \mathrm{m}$. The response to the pulsed electric fields started as low as $0.02 \mathrm{~V} / \mathrm{m}$ for one or two sensitive ones among a dozen crocodiles and $0.2 \mathrm{~V} / \mathrm{m}$ for all

When continuous air gap discharges of the high voltage sphere of a Van de Graaf electrostatic generator to the ground were made about $1 \mathrm{~m}$ away from these crocodiles, they closed their eyes. Neither intense light nor sound is produced by the discharge. This indicates that they are feeling the electric field of generated electromagnetic waves. Pro-

clear reaction was seen except sinking to the bottom of the pond and leaving the site. It is not possible to tell whether this result constitutes field-avoidance behavior.

\section{Birds}

Flamingos and geese were subjected to fields from 4 to $15 \mathrm{~V} / \mathrm{m}$. No clear reaction was seen except the puffing as observed for red sparrows in the previous work (Ikeya et al.1996). A goose seemed to notice the field application by on and off and showed slight convulsion at the field of $15 \mathrm{~V} / \mathrm{m}$. Penguins avoided the pool with electrodes where pulsed electric voltage was applied and gathered in another adjoining pool though food fish was in the former pool.

\section{Green snakes}

Snakes migrated into the Kobe-Oji Zoo to eat birds' eggs since the surrounding land area was devastated by the destruction. Several captured green snakes were placed on a wet towel spread in a box. Both DC and pulsed electric field from $1 \mathrm{~Hz}$ were applied to the snakes. The snakes muscle flexed as the field strength was increased to $100 \mathrm{~V} / \mathrm{m}$. Details of the responses to electric field are tabulated in Table 1. Photograph is given in Figure 3.

\section{Atagawa Banana-Alligator Garden}

Electric field effects on different species of crocodiles and alligators (Order Crocodylia) have been investigated for adult crocodiles with length greater than $2 \mathrm{~m}$, for young ones with the length of $1 \mathrm{~m}$ and for baby crocodiles of about $30 \mathrm{~cm}$.

\section{Alligators (Family Alligatoridae)}

Spectacled caiman (Caiman crocodilus (LINNE)): They seem to be sensitive to climate changes but have not shown clear SAAB prior to an earthquake. Young ones showed a startled movement to a DC electric field of $4 \mathrm{~V} / \mathrm{m}$ and bit the electrode at $5 \mathrm{~V} / \mathrm{m}$. duced field intensity is described later.

The body resistance measured at the back was more than 40 MW for most baby alligators and crocodiles, while the belly skin of some crocodile has exceptionally small resistance of $0.5-1 \mathrm{MW}$. Resistivity would be a main cause of individual sensitivity difference to the electric field and presumably to seismic electric field.

\section{Tortoise (Hieremis annandali Boulenger)}

The tortoises opened and closed their eyes similarly to crocodiles when the field of about $2 \mathrm{~V} / \mathrm{m}$ was applied. They then retracted their head. Behavior similar to that of a cat washing its face before a bad weather (as related with the Japanese folk story) was observed for a field intensity of $12 \mathrm{~V} / \mathrm{m}$. Eyes are organs with a direct electrical contact between the water and the body fluid for reptiles living in fresh water and so eye response to electric current may be anticipated.

The behavioral responses of snakes in the Banana-Alligator Garden and of other animals are tabulated in Table I together with the field intensity for some reptiles. Using these experimental field intensity, it is possible to use the retrospective $\mathrm{SAAB}$ reports to create the geographical distribution of the electric field as shown in the map. The field intensities are very high as compared with those of seismic electric signals $10^{-5} \mathrm{~V} / \mathrm{m}$, but may be reasonable because they are not static fields but very brief pulsed fields.

\section{Estimated seismic electric signal intensity}

\section{An electromagnetic model of a fault}

Our proposed electromagnetic model of fault behavior is based on the appearance of charge densities, $+q$ and $-q$ at the fault $z$ ne caused by the change of the seismic stress, $\sigma$ for the fault displace- 


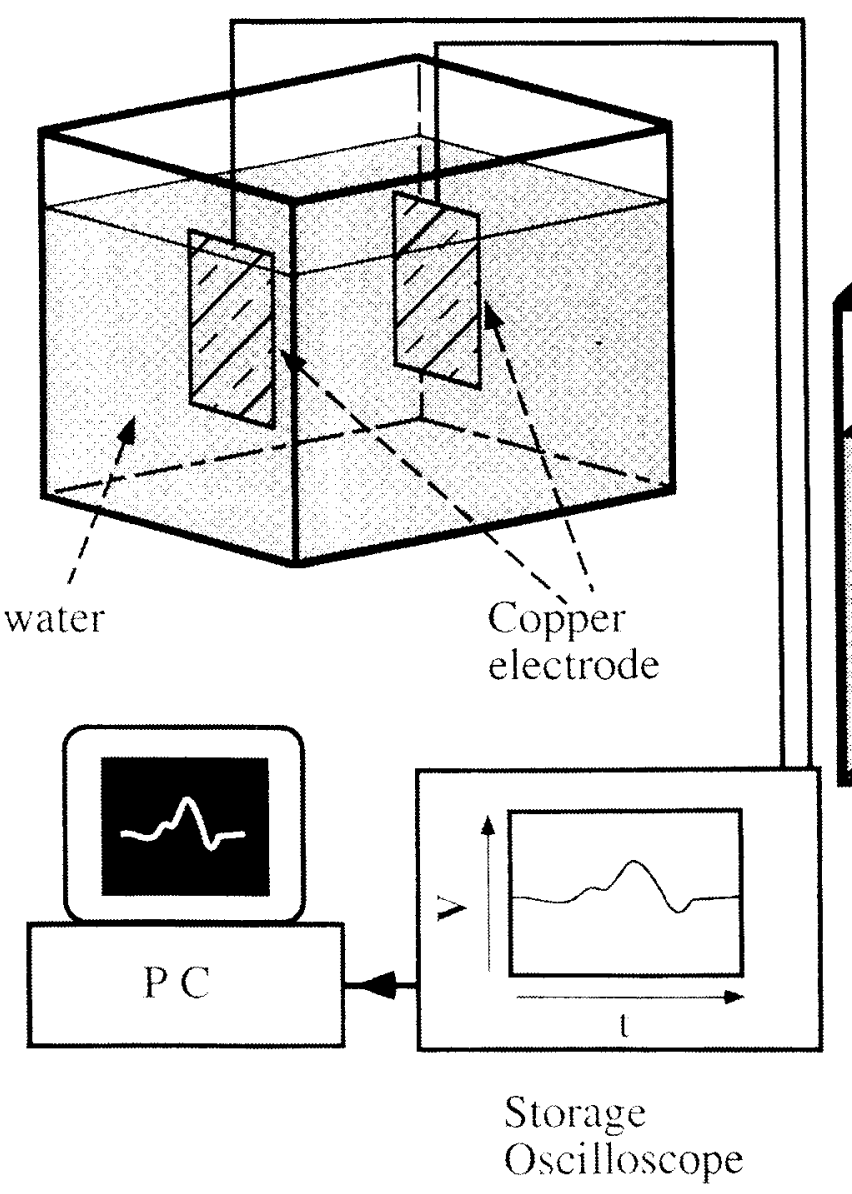

nent time or for the rock fracture time, $\tau$ (Ikeya and Takaki. 1996; lkeya et al.. 1996). The charges decay with a lime constant $\varepsilon \rho$, dependent upon dielectric constant, $\varepsilon$ and resistivity, $\rho$ of the earth. The mathematical model of a fault gives a time-dependent stress $\sigma(\tau)$ leadling to a pulsed charge density of $q(t)$ with risetime $\varepsilon \rho$ and decaly time $\tau$. The electric field intensity, $F(t)=q(t) / \varepsilon$ at a fault $\%$ one wals calculated using $\varepsilon \rho=70 \mu$ s for $\varepsilon^{*}=\varepsilon / \varepsilon_{0}=8$ and $\rho=10^{6} \Omega \cdot m$ for granite at a fault zone. Theoretical calculation of seismic field intensities in the form of electric pulses indicates peak intensitics hetween $10-100 \mathrm{~V} / \mathrm{m}$.

It was suggested that the above behavioral responses of animals i) electrical stimuli may be attributed to SAAB observed in experiments on tish with electrosensory organs and on birds and rats withbut them (Ikeya et al. 1996a, 1996b).

The seismic stress release due to fractures in rocks prior to the major shock, presumably resulting in pulsed currents because of the release of the piezo-compensated free charges. cannot be detected with the seismograph at $100 \mathrm{H} \%$. A high current density for local lactures along the fault prior to the main shock and focusing of the urrent for geographical reasons would explain SA $A B$ as electroohysiological response to the electric lield of electromagnetic waves.

\section{Electric field intensity estimated from SAAB}

Gapanese minnows have been observed to move quickly under elec ric lields ats small as $10 \mathrm{~V} / \mathrm{m}\left(0.2 \mathrm{~A} / \mathrm{m}^{2}\right)$, and to aligne themselves perpendicular to the field direction (Ikeya (t al. 1996). Sensitive inimows were paralyod at $50 \mathrm{~V} / \mathrm{m}$. but recovered soon responding (o) a single pulse with the widh of $0.1 \mathrm{~ms}$. The phenomena of fish digmment or paralyzed fish before the Kobe Earthquake, which was tated retrospectively by witnesses (Wadatsumi. 1995 ) might indi-

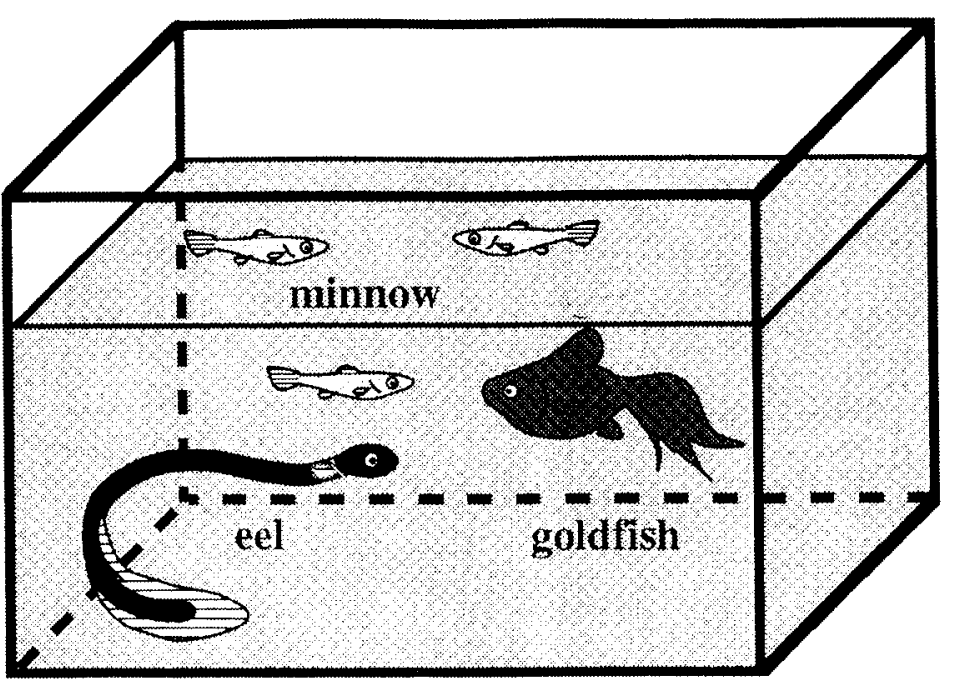

Figure 6 An aquarium with parallel plate electrodes besides an aquarium with eels, minnows and goldfish. The electric field in water was measured with a digital storage oscilloscope with a triggering level of $10 \mathrm{mV} / \mathrm{m}$ and stored into a computer with the time and the shape of the pulse.

cate the electric field intensities of more than $10 \mathrm{~V} / \mathrm{m}$ in nature before the Kobe Earthquake.

The responses of alligators are similar to those of minnows but those of crocodiles and sea lions are at least one or two orders of magnitude more sensitive than other animals owing to the presence of electrosensory organs with sensitivities of $0.1-200 \mathrm{mV} / \mathrm{m}$. The estimated field intensities and their directions are indicated on the map together with the percentage of animal anomalies before the Kobe Farthyuake in Figure 5 (a) as recalled by witnesses. We simply assume that the fish alionment is a seismic electric tield effect here.

Aquatic animals have a highly sensitive electrosensory system which is used 10 acquirc information for orientation and to communicate with others (Bastian, 1994: Bullock, 1983). Animals without such organs are thousands of limes less sensitive to electric fields. Fields of $10 \mathrm{~V} / \mathrm{m}$ are too intense for seismologists or geophysicist to accept from their experience of $10^{-5} \mathrm{~V} / \mathrm{m}$ as a typical seismic electric field (SES), which lead to rejection of this work. However, only ultra low lrequency (ULI') electromagnetic waves out of a wave-packet may have been measured at long distances from the epicenter in their casc. The pulsed field intensity close to the epicenter must have been around $10 \mathrm{~V} / \mathrm{m}$ in order to cause $\mathrm{SAAB}$ to ordinary animals without electrosensory organs. Electric stimuli to cyes and skins will lead to field-avoidance behavior:

Chinese seismologists observed high pulsed electric fields before the Tangshan Farthquake. but unfortunately discarded the data considering them as crrots in the electrometer. What animals detected may be the pulsed flow of eharges at the stress-released areal around the faul zone; the peak intensity is high though the duration is less than $1 \mathrm{~ms}$ according 10 our theory. Animals would be responding 10 an abrupt change in the local electric field of the clectromagnetic waves caused by the seismic charges. 
(a)

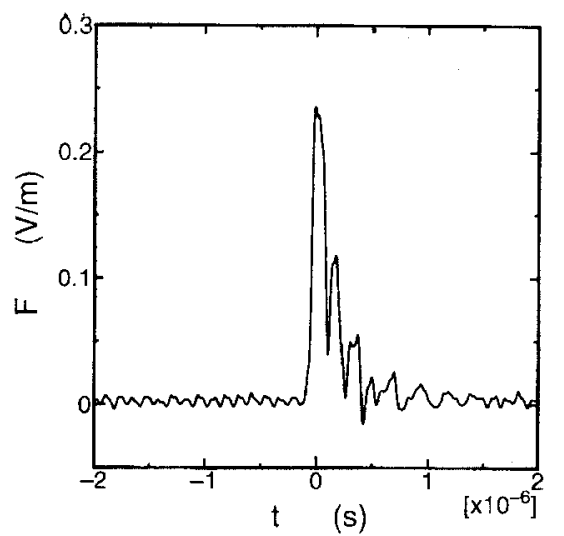

(b)

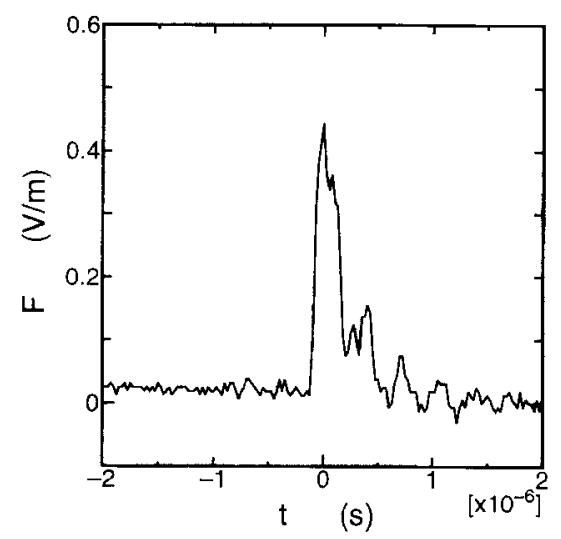

(c)

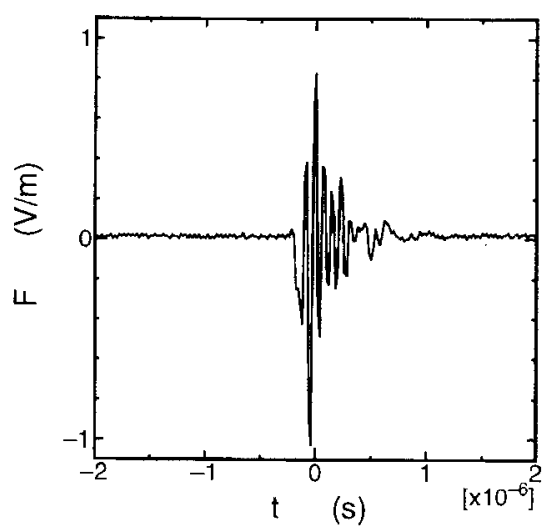

Figure 7 The output of digital storage oscilloscope of electric pulse voltage detected in a laboratory (a) at the time of nearby atmospheric lightning, and (b) one of the five pulses happen to be observed one hour before an earthquake of the magnitude 3.9. Correlation with the earthquake is not clear. (c) Electric noises induced by switching of a phosphorescent lamp in a laboratory.

\section{Measurement of electric field by lightning, Van de Graaff discharges and unknown}

Electric pulses would propagate as wave packets, i. e., a number of electromagnetic waves having different frequencies (Ikeya et al., 1997). The seismic pulse signals from a fault may be detected with a modern electronic technique, such as using a digital storage oscilloscope (DSO) with a triggering level for recording. A parallel plate electrodes were placed in an aquarium and the voltage was measured with the DSO as is schematically shown in Figure 6. A derivative form of pulsed electric field is to be measured with this apparatus. Figure 7(a) shows electric pulses observed at the nearby atmospheric lightning by setting the triggering level of $10 \mathrm{mV}$. Electric noise pulses were observed as shown in (b) by air-gap discharges from the high voltage sphere of a Van de Graaff electrostatic generator by setting a grounded wire close to the sphere. The pulse widths are of the order of $0.1 \mathrm{~ms}$. We observed different pulses with a width of $1 \mu \mathrm{s}$ in the laboratory as shown in (c). It is interesting to note that eels in this laboratory aquarium showed startled movements and hamsters washed face and screamed by fighting with each others. No change in the behavior was noticed for minnow and goldfish.

An earthquake of magnitude, $M=3.9$ occurred 3.2 days later. Unfortunately, it is not possible to link these electric pulses and animal behavior to the earthquake since the campus is surrounded by the source of electric noises, monorails, heavy traffic roads, nuclear accelerator, etc. However, Rikitake's empirical formula of the relation between the precursor time, $T$ and the magnitude $M$, i. e., $\log _{10} T$ $=0.37 M-0.89$ for the SAAB gives 3.5 days and the area $R$ of the SAAB appearance is obtained from $M=2.67 \log R_{\max }-0.91$ as $R_{\max }$ $=70 \mathrm{~km}$. The epicenter $35 \mathrm{~km}$ away from the observation campus is well within this distance. Unless we determine the source of the electric pulses, it is not possible to ascribe the observed pulses to an earthquake precursor.

Atmospheric lightning and artificial discharges using a Van de Graaff electrostatic generator also caused electric pulses in water and sudden movement of eels and grooming of hamsters. Minnows and goldfish seemed less sensitive at that time. They respond to the electric field of more than $10 \mathrm{~V} / \mathrm{m}$ (Ikeya et al., 1996a), while eels responded to the field of less than $1 \mathrm{~V} / \mathrm{m}$.

\section{Discussion}

It would be possible to improve some of the experiments by use of several recording equipment with cooperation of zoos. Animals are kept under specialist care at thousands of zoos all over the world.
Animal's behavior in relatively controlled conditions may be watched daily by professional keepers with scientific backgrounds. Video recorders adopted to cyclic tape continuously or triggered by environmental electric pulses could record behavior. Statistical comparison of behavior should give an objective measure of the effects of such pulses whether they are from lightning, earthquake or other origins. Therefore, anomalous behaviors may be noticed without difficulties if $\mathrm{SAAB}$ are well categorized and scientifically understood as behavioral responses to electric pulse stimuli or to electric field of electromagnetic waves. It would be best to set up such equipment in countries prone to earthquake, and preferentially monitor sensitive species such as sea lion, crocodile and eels.

Anomalous behavior of eels, birds and rats was also observed in preliminary fracture experiments of granitic rocks using 200 and 500 ton compression machines simultaneously with the detection of electromagnetic waves as described separately elsewhere. Both phenomena preceded above $10^{7} \mathrm{~Pa}$ well before the fractures at $10^{8} \mathrm{~Pa}$ and the detection of acoustic emissions by piezoelectric sensor attached to the rock. Although detailed work will be published elsewhere, the observation indicates that $\mathrm{SAAB}$ and electromagnetic wave generation are common phenomena before the main shock. The determination of the precursor time is the main difficulty in earthquake prediction using SES.

It would be particularly interesting to determine whether an early stage earthquake warning well before the arrival of seismic Pand $\mathrm{S}$-waves might be made by electronic detection of seismic pulses rather than from the observation of SAAB; the exact triangulation of time and place of pulse origins would be difficult to determine without recording observational data at several places using global positioning system (GPS) clocks. Considering the speed of light, Pwaves and $\mathrm{S}$-waves, the $\mathrm{S}$-waves which cause disaster come after $\mathrm{P}$ waves arrive in a time with the same interval between the observation of coseismic electromagnetic waves and the P-waves.

\section{Conclusion}

This paper asserts that $\mathrm{SAAB}$ is not a superscientific phenomenon, but behavioral response to electrical stimuli and that a pulsed seismic field intensity of about $10 \mathrm{~V} / \mathrm{m}$ before the Kobe Earthquake must have caused panic to ordinary animals at the Kobe-Oji Zoo. The responses of sea lions at $0.5 \mathrm{~V} / \mathrm{m}$ and crocodiles down to $0.02 \mathrm{mV} / \mathrm{m}$ similar to the field which surprised eels was confirmed in the experiment of electric field effects. Animals showed the same behavior as electric field effects in experiments of rock fractures using a 500 ton 
press machine. Most of reported SAAB in the Kobe Earthquake is similar to reported behavior before atmospheric lightning.

\section{Acknowledgment}

We thank the animal keepers at the Kobe-Oji Zoo and Izu-Atagawa Banana-Alligator Zoo for their cooperation and S. Huang, D. Takashimizu and undergraduate students for help in the experiment, Mr. L. Cull in Osaka Uni., Dr. W. C. Mallard at Georgia State Univ. and Dr. N. Whitehead at DSIR, New Zealand for their critical reading of the manuscript .

\section{References}

Abe, N., 1934, On the behavior of catfish in response to galvanic stimuli: Sci. Rep. Tohoku Imp. Univ. Biol. v. IX, pp. 87-96.

Bastian, J., 1994. Electrosensory organs of aquatic animals: Physics Today v. 47 , pp. 30-37.

Biophysics Institute, Academica Sinica ed., 1977, Animals Informs Earthquake., Beijing, China: Japanese translation published by Nagasaki Publisher.

Brady, B.T. and Rowell, G.A., 1986, Laboratory investigation of the electrodynamics of rock fracture: Nature v. 321, pp. 488-492.

Bullock, T.H., Bodoznick, D.A., and Northcutt, R.G., 1983, The phylogenetic distribution of electroreception: Evidence for convergent evolution of a primitive vertebrate sense modality: Brain Research Review, v. 6, pp. 25-46.

Bushirk, R.E.. Frohlich, C. and Latha G.V.. 1981, Unusual animal behaviors before earthquakes: A review of possible sensory mechanisms: Rev. Geophys. \& Space Phys. v. 19, pp. 247-270

Huang, Q. and Ikeya, M., 1997. Electric field effects on animals: Mechanism of seismic anomalous animal behavior (SAAB): Earthquake Research in China v. II, pp. 109-118.

Ikeya, M.. 1993, New Applications of Electron Spin Resonance - Dating. Dosimetry and Microscopy: World Scientific, Singapore, pp500.

Ikeya, M. Takaki, S., 1996, Electromagnetic model of a fault for earthquake lightnings (EQLs): Jpn. J. Appl. Phys. v. 35. pp. 355-357.

Ikeya, M., Takaki, S. and Takashimizu, S., 1996a, Electric shocks for seismic animal anomalous behaviors (SAABs): J. Phys. Soc. Japan v, 65, pp. $710-713$

Ikeya, M., Furuta, H., Kajiwara, N., Anzai, H., 1996b. Ground electric field effects on rats and sparrows for seismic animal anomalous behaviors (SAABs): Jpn J. Appl. Phys. v. 65, pp. 4587-4594.

Ikeya, M., Takaki, S., Matsumoto, H., Tani, A. and Komatsu, T., 1997. Pulsed charge model of a fault behavior producing seismic electric signals: J. Circuits. Systems and Computers v. 7, pp. 153-164.

Ikeya, M. and Matsumoto, H. 1997, Reproduced earthquake precursor legends using a Van de Graaff electrostatic generator:: Candle flame and dropped nails: Naturwissenschaften, v.84, No.12, (in press).

Lockner, D.A., Johston, M.J.S, and Byerlee, J.D., 1983, A mechanism to explain the generation of earthquake lights: Nature v. 302, pp. 28-33.

Masuya, K., 1995, Earthquake Catfish : Akashi Publisher, Tokyo (in Japanese).

Misakian, M., Sheppard, A.R., Krause. D., Frazer. M.E. and Miller, D.L.. 1993, Biological, physical, and electrical parameters for in vitro studies with ELF magnetic and electric fields: A primer: Bioelectromagnetics Suppl. v, 2, 1-25.
Rikitake, T., 1978, Biosystem behaviour as an earthquake precursor: Tectonophys. v. 35 , pp. $335-362$.

Tributch, H., 1978, Do aerosol anomalies precede earthquake ?: Nature v. 276, pp. 606-608.

Varatos, P. and Alexopoulos, K., 1984, Physical properties of the variations of the electric field of the Earth preceding earthquakes: Tectonophysics v. 110 , pp. 73-98.

Wadatumi, K., 1995, 1591 Witnesses Prior to Earthquake: Tokyo Pub, Tokyo, pp. 267 (in Japanese).

Motoji Ikeya, Professor, graduated from Department of Electronic Engineering in 1963 and moved to Nuclear engineering in Graduate School, Osaka University. PhD for studying radiation effects in solids with electron spin resonance (ESR). Interdisciplinary studies of ESR dating in geology and archaeology were made at Yamaguchi Uni. (1973-87) and also in Physics Dept. of Osaka Uni. (1987-91). Earthquake precursor studies since the Kobe earthquake in 1995.

\begin{abstract}
Masayoshi Gondou, Graduated from Department of Veterinary Medicine, Faculty of Agriculture, Gifu University in 1960 and employed by Kobe city. Obtained MD from Department of Medicine, Kobe University for physiological research on bird eyes. Director of the Kobe-Oji Zoo from 1993 and lecturer of Kobe University teaching Wild Animal Zoology.
\end{abstract}

Mr Takahide Komatsu is Master course student observing seismic pulsed electric field.
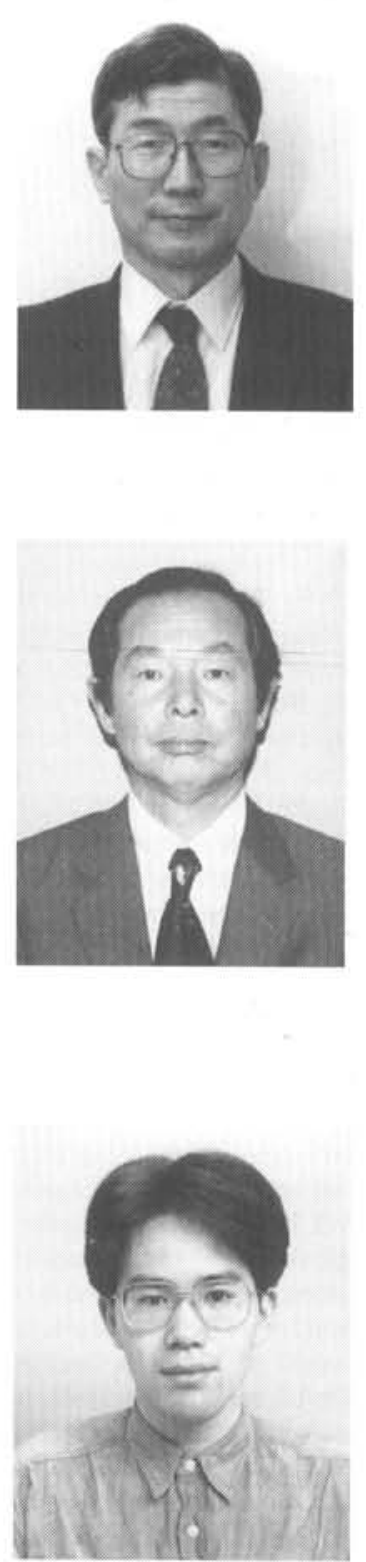